\title{
Coalitions in the triad: Additive case.
}

\author{
RICHARD H. WILLIS, I University of \\ Pittsburgh, Pittsburgh, Pa. 15213
}

Like-sexed triads played 36 games of chance in which the objective was to earn as many points for oneself as possible. On each trial, players were allowed to form coalitions, if desired, but expected value of winnings was exactly equal to that for members playing individually. Contrary to predictions, coalitions were formed frequently-on $57 \%$ of all trials. A strong tendency was observed for equals and near-equals to favor one another as coalition partners. A second strong effect was for weaker players to band together. Division of points won deviated markedly from equity in the direction of equality.

Within the last decade, a rather large number of experimental studies of coalition formation in small groups have been reported (e.g., Vinacke \& Arkoff, 1957; Willis, 1962). The major independent variable in these studies has been the distribution of power within the group, where the power of a group member refers to the amount of his resources contributing to the control of outcomes. An example of such resources would be votes in a group in which outcomes are determined by elections.

Certain theorists, such as Caplow (1956, $1959,1968)$, Gamson $(1961,1964)$, and Riker (1962) have concerned themselves-rather successfully-with the problem of predicting the relative frequencies with which various types of coalitions are formed under specified distributions of power, although the problem of predicting absolute frequencies has been almost totally ignored. A major predictive principle is that coalitions are preferred that are just barely powerful enough to control the outcome. For this principle to apply, it is necessary that there be a critical level of power beyond which control of the outcome is assured. If 100 votes are divided among the several members of a group in which an election is determined by a simple majority, for example, any coalition controlling more than 50 votes is necessarily a winning coalition. Under such conditions, certain coalitions can do much better for their members than the members can do for themselves, each operating alone. In the terminology of game theory, such a situation constitutes an essential game (Luce \& Raiffa, 1957).

In the present experiment, a three-person group situation was employed in which the formation of coalitions is neither advantageous nor disadvantageous from the standpoint of both coalition members taken together. The expected return to the coalition is exactly equal to the sum of the expected returns to its members playing individually, so that one can refer here to the additive case. This is also, in the terminology of game theory, an inessential game. The game was rendered additive, or inessential, by introducing a probabilistic relationship between power and winning and by setting the probability of a coalition winning equal to the sum of the probabilities for the individual members playing alone. The stake on each trial was held constant.

For any particular member in a given coalition, however, an advantage or a disadvantage could accrue as a function of the agreement reached with the partner about division of points. Still, if members anticipate dividing points in proportion to resources contributed-and this is the assumption of a parity norm that is basic to Gamson's theory of coalitions-then coalescing will be perceived to be neither advantageous nor disadvantageous. On the other hand, if the parity norm does not hold, then one of the prospective partners will be better off playing alone. In summary, if the parity norm does hold, coalitions are pointless; if it doesn't, they are worse than pointless for someone. In either case, one is led to the prediction that very few coalitions will be formed.
This prediction assumes that players will behave "rationally," by which is meant that their sole objective is to maximize winnings and that they adopt efficient means for realizing this objective. METHOD

The Ss were 168 undergraduate volunteers at the University of the Philippines. From these were formed 56 three-person groups, half males only and half females only. Es were seven graduate students in sociology.

Each group played 36 trials of a game of chance in which the objective, as stated by the $E$, was to earn as many points for onself as possible. Over the 36 trials, eight different conditions of power distribution were introduced. The three power coefficients assigned to $\mathrm{Ss}$ always summed to 10 , and each unit of power represented a $10 \%$ chance of winning on a given trial. Thus, a coefficient of 5 meant that the player had a $50 \%$ chance of winning. On each trial, the winner received 100 points.

Players were allowed to form coalitions during 1 -min negotiation periods preceding each trial. If two players coalesced, the coalition had a power coefficient equal to the sum of the two individual coefficients. Partners were required to agree beforehand on the division of points, and coalitions were valid for one trial only.

All possible assignments of power coefficients to specific group members were made once, and the order of assignments within each condition was determined by chance. Each of the seven Es ran eight groups, each group confronting the eight conditions in a different sequence. Sequences were chosen

Table 1

Coalitions Formed in Each Condition of Power Distribution

\begin{tabular}{|c|c|c|c|c|c|c|c|}
\hline \multicolumn{2}{|c|}{ (1) } & $(2)$ & (3) & (4) & $\begin{array}{l}\text { (5) } \\
\text { quen }\end{array}$ & & \multirow{2}{*}{$\begin{array}{c}(7) \\
O / E \\
M+F\end{array}$} \\
\hline \multicolumn{2}{|c|}{ Condition } & Frequency & $\%$ & $\mathbf{M}$ & $\mathbf{F}$ & $\mathbf{M}+\mathbf{F}$ & \\
\hline $\mathbf{A}$ & $\begin{array}{l}8-1 \\
1-1\end{array}$ & 110 & 65.5 & $\begin{array}{l}14 \\
40\end{array}$ & $\begin{array}{l}33 \\
23\end{array}$ & $\begin{array}{l}47 \\
63\end{array}$ & $\begin{array}{r}.64 \\
1.72\end{array}$ \\
\hline B & $\begin{array}{l}6-2 \\
2-2\end{array}$ & 115 & 68.4 & $\begin{array}{l}18 \\
35\end{array}$ & $\begin{array}{l}29 \\
33\end{array}$ & $\begin{array}{l}47 \\
68\end{array}$ & $\begin{array}{r}.61 \\
1.77\end{array}$ \\
\hline $\mathrm{C}$ & $\begin{array}{l}4-3 \\
3-3\end{array}$ & 85 & 50.6 & $\begin{array}{l}21 \\
22\end{array}$ & $\begin{array}{l}22 \\
20\end{array}$ & $\begin{array}{l}43 \\
42\end{array}$ & $\begin{array}{r}.76 \\
1.48\end{array}$ \\
\hline D & $\begin{array}{l}4-4 \\
4-2\end{array}$ & 90 & 53.6 & $\begin{array}{l}21 \\
25\end{array}$ & $\begin{array}{l}20 \\
24\end{array}$ & $\begin{array}{l}41 \\
49\end{array}$ & $\begin{array}{r}1.37 \\
.82\end{array}$ \\
\hline $\mathbf{E}$ & $\begin{array}{l}7-2 \\
7-1 \\
2-1\end{array}$ & 200 & 59.5 & $\begin{array}{r}7 \\
31 \\
63\end{array}$ & $\begin{array}{l}26 \\
28 \\
45\end{array}$ & $\begin{array}{r}33 \\
59 \\
108\end{array}$ & $\begin{array}{r}.50 \\
.88 \\
1.62\end{array}$ \\
\hline $\mathbf{F}$ & $\begin{array}{l}6-3 \\
6-1 \\
3-1\end{array}$ & 193 & 57.4 & $\begin{array}{l}15 \\
26 \\
52\end{array}$ & $\begin{array}{l}24 \\
35 \\
41\end{array}$ & $\begin{array}{l}39 \\
61 \\
93\end{array}$ & $\begin{array}{r}.61 \\
.95 \\
1.45\end{array}$ \\
\hline $\mathbf{G}$ & $\begin{array}{l}5-3 \\
5-2 \\
3-2\end{array}$ & 184 & 54.8 & $\begin{array}{l}23 \\
16 \\
50\end{array}$ & $\begin{array}{l}20 \\
31 \\
44\end{array}$ & $\begin{array}{l}43 \\
47 \\
94\end{array}$ & $\begin{array}{r}.70 \\
.77 \\
1.53\end{array}$ \\
\hline $\mathbf{H}$ & $\begin{array}{l}5-4 \\
5-1 \\
4-1\end{array}$ & 174 & 51.8 & $\begin{array}{l}18 \\
24 \\
35 \\
\end{array}$ & $\begin{array}{l}20 \\
36 \\
41 \\
\end{array}$ & $\begin{array}{l}38 \\
60 \\
76 \\
\end{array}$ & $\begin{array}{r}.66 \\
1.03 \\
1.31 \\
\end{array}$ \\
\hline
\end{tabular}


so that each E's groups completed one replication of a balanced Latin square RESULTS

Results are shown in Table 1. Column 1 indicates types of coalitions possible under each experimental condition, while Column 2 shows the number of coalitions formed in each condition. From Column 3, which gives percentages, it can be seen that coalitions were formed on the majority of trials in each condition. Over all conditions, coalitions occurred on $57 \%$ of the trials. The prediction of very few coalitions, deriving from the inessential nature of the game, is clearly contradicted by the data. Ss did not play "rationally" in the narrow sense of this term given earlier. It should be noted, however, that essential games typically induce Ss to coalesce even more often-on more than $80 \%$ of all trials (e.g., Lieberman, 1962; Vinacke \& Arkoff, 1957; Vinacke, 1959; Willis, 1962).

The relationship between distribution of power and frequency of coalitions is also apparent from Column 3. The four conditions with the highest proportions are those with a power coefficient of 6 or above. The four conditions with the lowest proportions are those with a more even distribution of power, having no coefficient larger than 4 or 5 . This degree of consistency is significant at the .05 level by a two-tailed exact-probability test. Coalitions are formed especially often when the two weak players are equally weak, as in Conditions A and B.

The distributions of coalitions of each type within each condition are presented for groups of males, for groups of females, and for all groups combined, in Columns 4 , 5 , and 6. In Column 7 is shown the ratio of observed frequencies to expected frequencies, for all groups. Two intracondition patterns are evident. First, weaker coalitions are formed more often than are stronger ones, both absolutely and relative to expected frequencies. Second, with coalition strength held constant, equals coalesce more often than do nonequals.

The first effect can be seen quite easily in Column 7, which provides 16 relevant comparisons. With only one exception, the observed/expected $(\mathrm{O} / \mathrm{E})$ frequency ratio is larger for the weaker coalition-a highly significant degree of consistency. From an examination of Columns 4 and 5, one sees that the tendency for weaker players to coalesce is substantially stronger among males.
Only in Condition $D$ is the $O / E$ ratio larger for the stronger coalition, but this is the only instance in which the stronger coalition is between equals. In this case, the equality effect outweighed the weakness effect. From Columns 4 and 5, it is possible to make 12 comparisons relevant to this equality effect, and in all cases coalitions between equals are more frequent than those of the same strength but between nonequals. The sign test shows this trend to be highly significant.

In view of the relatively large number of coalitions formed, one might suspect that the parity norm was operating in these groups, since deviations from this norm imply that one member of any potential coalition would be able to do better alone. It is perhaps surprising, then, that an analysis of agreements reached between partners reveals that the parity norm was rather flagrantly violated. There was a pronounced bias in favor of the junior partner. The less powerful partner can generally command a more-thanproportional share of the winnings. This bias is much stronger for females than it is for males.

The same difference between sexes appears from an analysis of 50-50 deals. Such even splits occur quite frequently among both sexes, but were observed more often in females, to the extent of $66.0 \%$ vs $40.1 \%$. Between unequal partners, the difference between sexes is dramatic $-60.3 \%$ for females and $24.7 \%$ for males.

\section{DISCUSSION}

The general picture that emerges is one of "irrational" behavior, where rationality is defined in terms of the E-imposed objective of earning as many points as possible. Furthermore, females are more "irrational" than males, for they form more coalitions than males do, despite a greater deviation from the parity norm, and agree upon many more 50-50 splits between partners of unequal strength.

Of course, it may be that these Ss appear to behave irrationally because the wrong definition of rationality has been applied. Perhaps they had other motives besides that of winning points and were, in fact, employing strategies that were rather effective in gratifying these other motives. To give just one example, forming coalitions may have been more fun than going it alone all the time, either because of an involvement in the negotiations or because of a preference for winning smaller amounts more often over the same total number of points in fewer, larger payoffs.

Another motive to coalesce may have derived from the social cost of saying, "No." Observers of both cultures consistently judge such costs to be higher in Filipino society than in our own. An American sample might well have formed fewer coalitions, but at present this is only a speculation.

The most important general implication of this study is that the expected value of manifest rewards provides an inadequate basis for predicting either absolute or relative frequencies of coalitions formed. "Hidden" rewards, as well as such manifest ones as points or money payoffs, must also be taken into account.

\section{REFERENCES}

CAPLOW, T. A theory of coalitions in the triad American Sociological Review, 1956, 21, 489-493.

CAPLOW, T. Further developments of a theory of coalitions in the triad. American Journal of Sociology, 1959, 64, 488-493.

CAPLOW, T. Two against one: Coalitions in triads Englewood Cliffs, N.J.: Prentice-Hall, 1968.

GAMSON, W. A. A theory of coalition formation. American Sociological Review, 1961, 26, 373-382.

GAMSON, W. A. Experimental studies of coalition formation. In L. Berkowitz (Ed.), Advances in experimental social psychology. Vol. 1. New York \& London: Academic Press, 1964. Pp. 82-110.

LIEBERMAN, B. Experimental studies of conflict in some two-person and three-person games. In J. H. Criswell, H. Solomon, and P. Suppes (Eds.), Mathematical methods in small group processes. Stanford, Calif:: Stanford University Press, 1962. Pp. 203-220.

LUCE, R. D., \& RAIFFA, H. Games and decisions New York: Wiley, 1957.

RIKER, W. H. The theory of political coalitions New Haven \& London: Yale University Press, 1962.

VINACKE, W. E. Sex roles in a three-person game. Sociometry, 1959, 22, 343-360.

VINACKE, W. E., \& ARKOFF, A. An experimental study of coalitions in the triad. American Sociological Review, 1957, 22, 406-414.

WILLIS, R. H. Coalitions in the tetrad. Sociometry, 1962, 25, 358-376.

\section{NOTE}

1. The reported experiment was conducted while the author was a Rockefeller Foundation visiting professor at the University of the Philippines. Thanks are due the following graduate students who served as Es: Virginia Atvarez, Rodolfo Bulatao, Marlene Ligan, Amelita Liggayu, Elizabeth Quimpo, Ana Maria Rotor, and Maria Vida Ventura. 